\title{
Enantiomeric Switching of the Circularly Polarized Luminescence Processes in a Hierarchical Biomimetic System by Film Tilting
}

Michidmaa Khorloo, \#a Xiaoxiao Yu,\# $\#^{\mathrm{b}}$ Yanhua Cheng, ${ }^{* \mathrm{~b}}$ Haoke Zhang, ${ }^{\mathrm{a}}$ Senlong Yu, ${ }^{\mathrm{b}}$ Jacky W. Y. Lam, ${ }^{\text {a }}$ Meifang Zhu*b and Ben Zhong Tang*acd

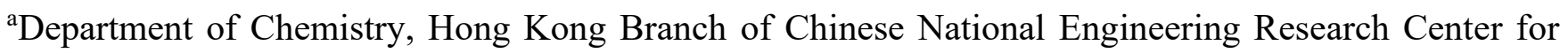
Tissue Restoration and Reconstruction, Institute for Advanced Study and Development of Chemical and Biological Engineering, The Hong Kong University of Science and Technology, Clear Water Bay, Kowloon, Hong Kong, China.

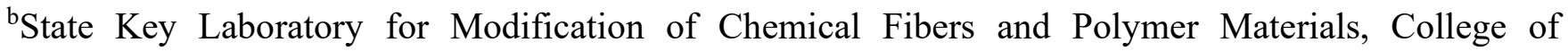
Materials Science and Engineering, Donghua University, Shanghai, 201620, China.

cAIE Institute, Guangzhou Development District, Huangpu, Gunagzhou 510530, China

${ }^{\mathrm{d} C e n t e r}$ for Aggregation-Induced Emission, SCUT-HKUST Joint Research Institute, State Key Laboratory of Luminescent Materials and Devices, South China University of Technology, Guangzhou 510640, China. 


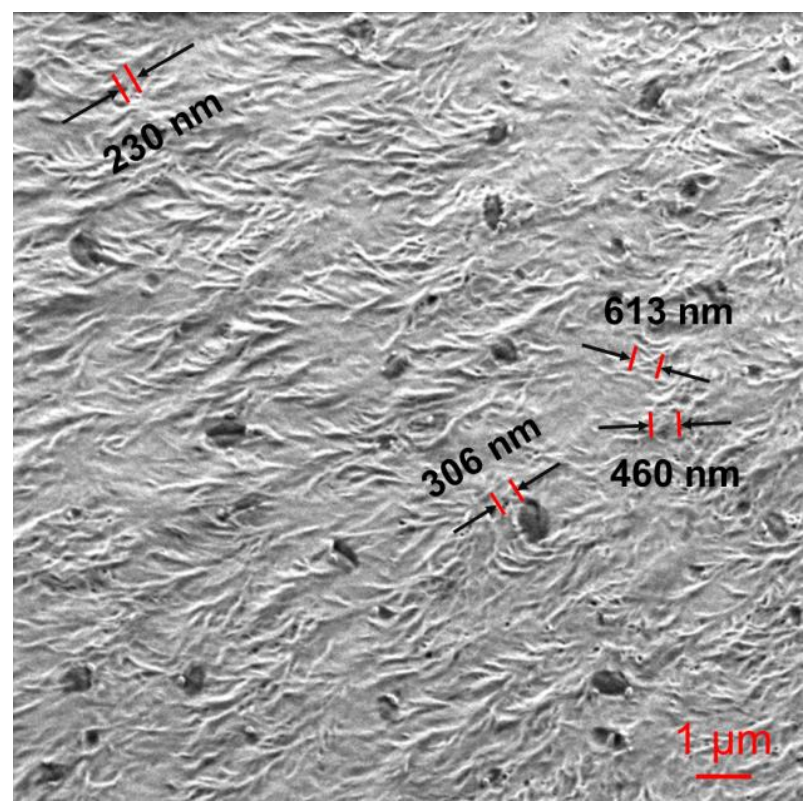

Figure S1. SEM image of twisted crystallites of BCC-Y. Randomly-distributed helical pitches are indicated in the SEM image.

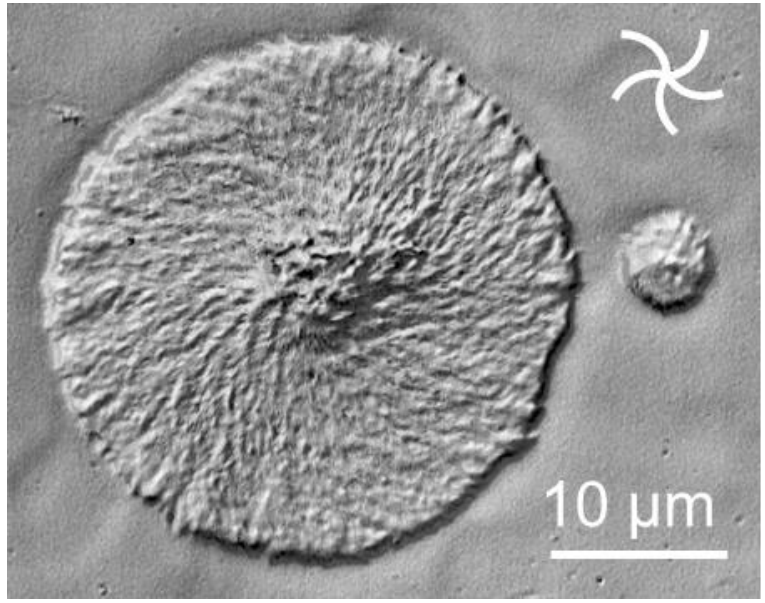

Figure S2. Laser scanning confocal image of BCC-Y (top view), twisted crystallites are organized to construct into a 3D anti-clockwise spiral. 


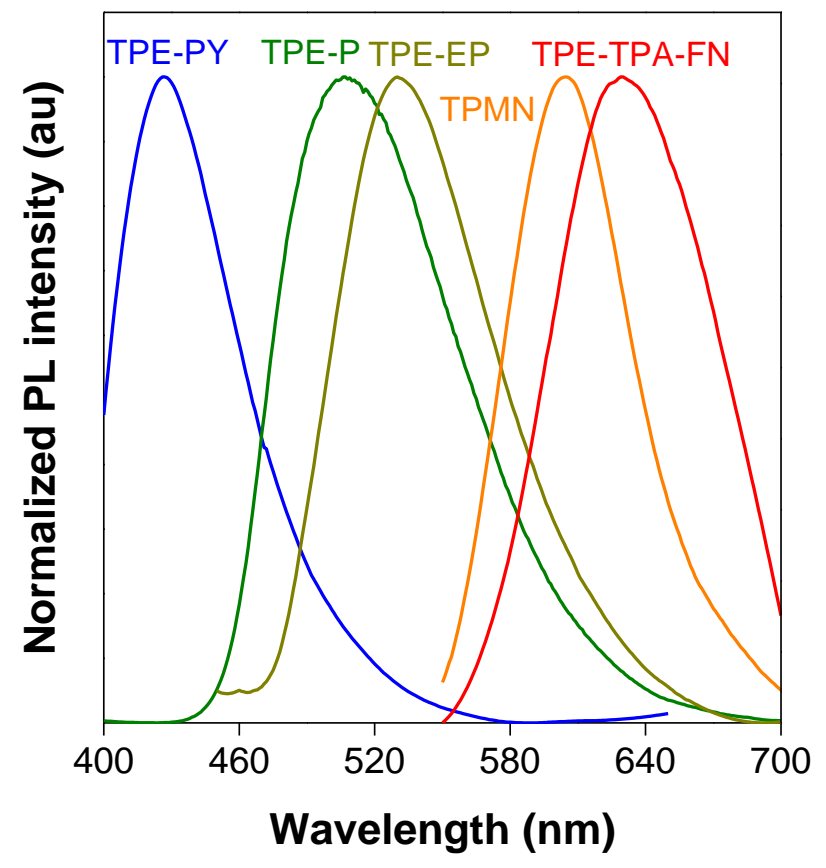

Figure S3. PL emission spectra of various AIEgens in the solid powder state.
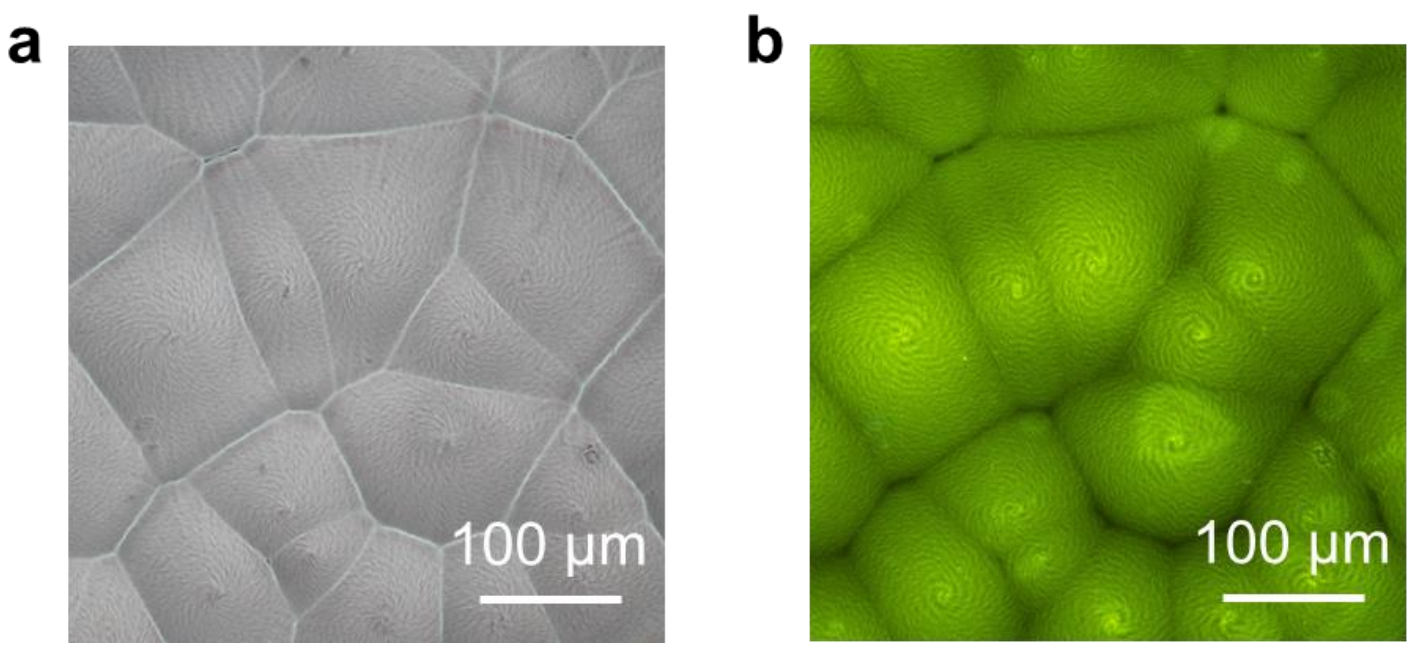

Figure S4. (a) Bright-field and (b) fluorescence microscope images of BCC-Y film, consisting interlinked chiral spherulites. 


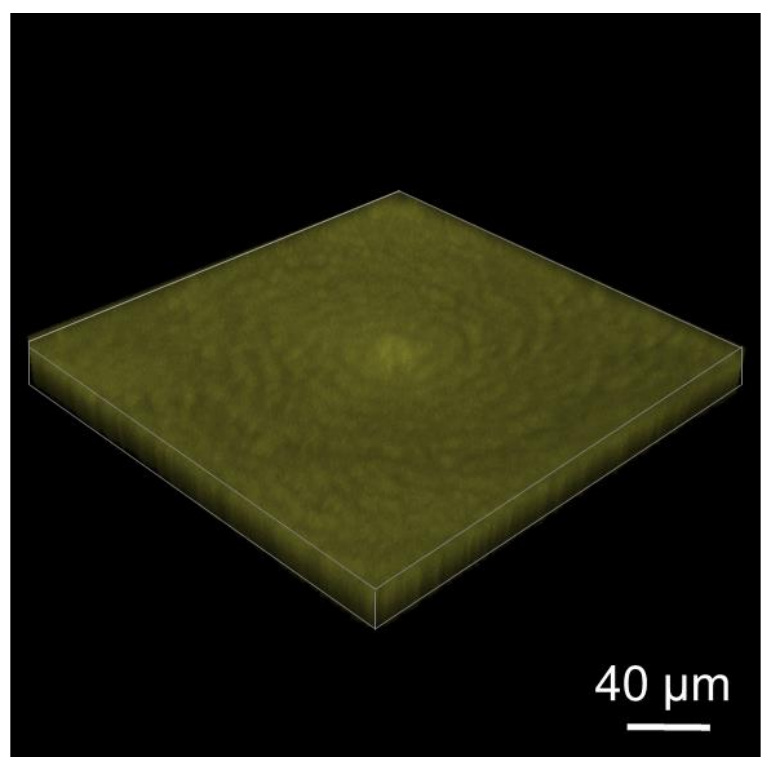

Figure S5. Microscopic fluorescence confocal representation of BCC-Y, indicating a 3D anti-clockwise structure of the spherulite.
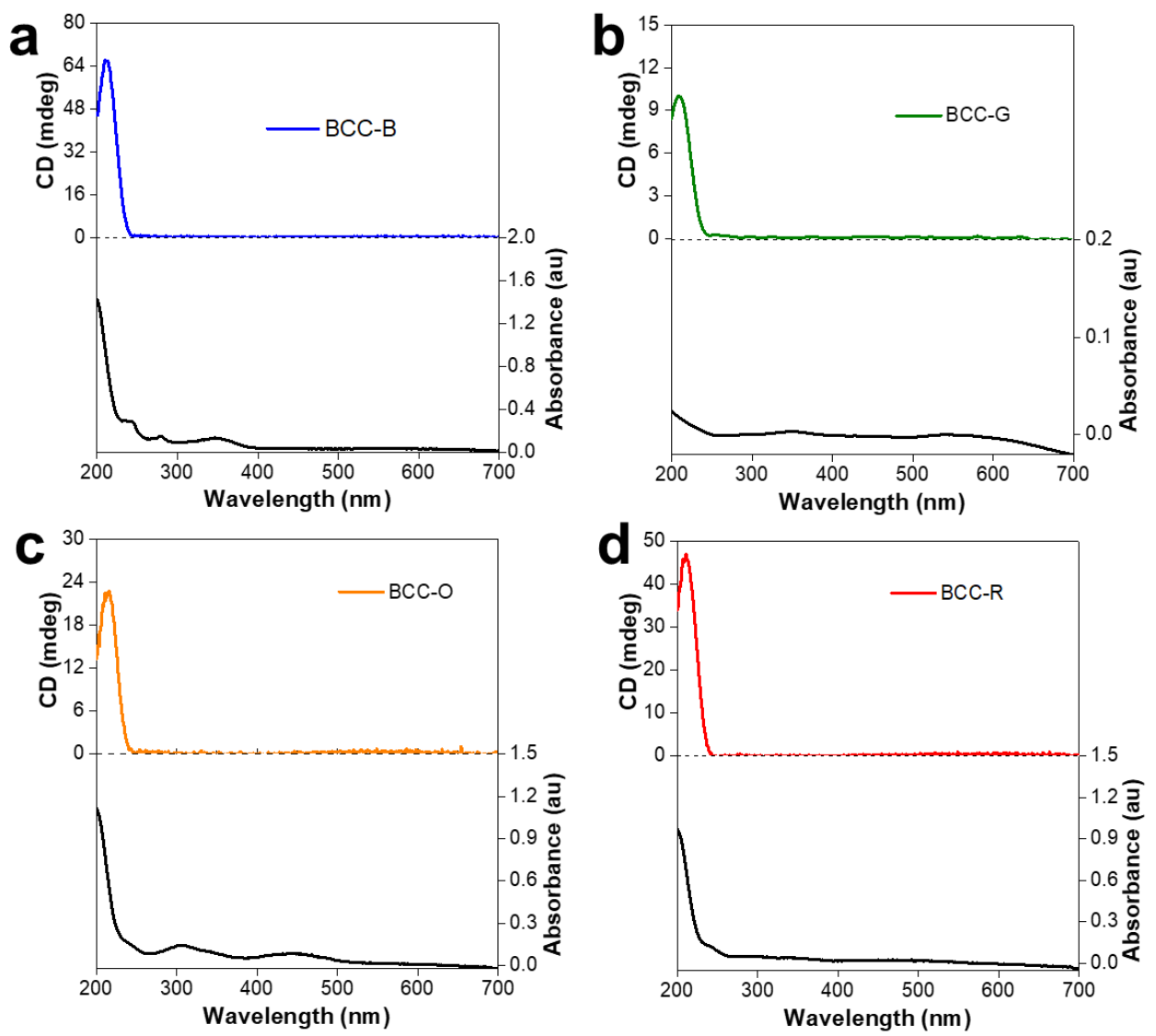

Figure S6. CD spectra of (a) BCC-B, (b) BCC-G, (c) BCC-O, and (d) BCC-R. All BCC-X systems showed no CD signal corresponding to the embedded AIEgens, indicating the absence of transfer of chirality. 
$\mathbf{a}$

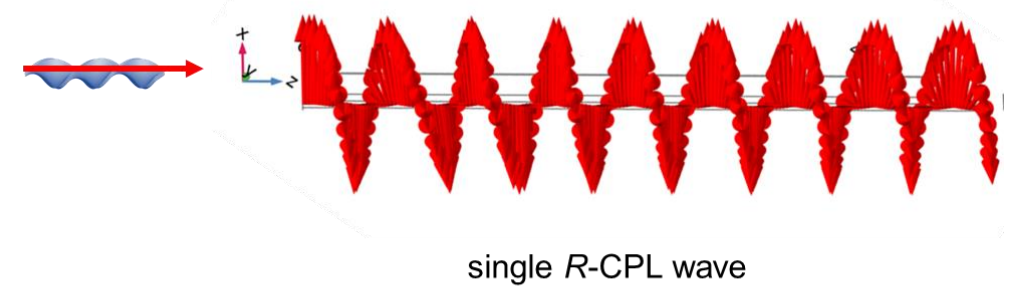

b
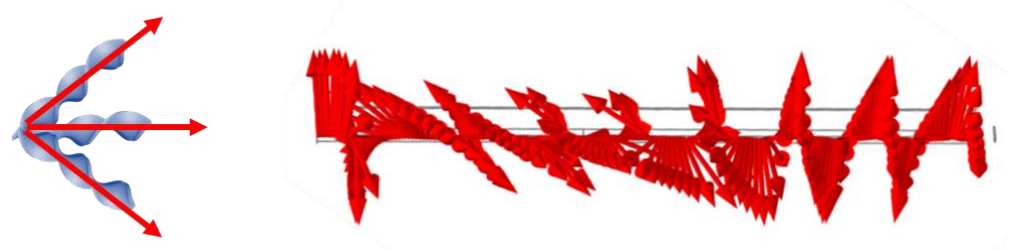

three superimposed $R$-CPL waves

Figure S7. Optical properties of light transmitted from the (a) single crystallite and (b) top hemisphere of spherulite simulated by finite-element method. To simplify the model, three crystallites with $45^{\circ}$ angle were selected to stand for the top hemisphere of the chiral spherulite.

According to the mechanism of selective reflection and transmission, in panel a, the transmitted circularly polarized light is right-handed. The handedness could be verified from the electric field vectors of a circularly polarized electromagnetic wave. For the top hemisphere, in panel $b$, three beams of $R$-CPL were transmitted simultaneously, the collected waves were demonstrated to be also righthanded. 
a

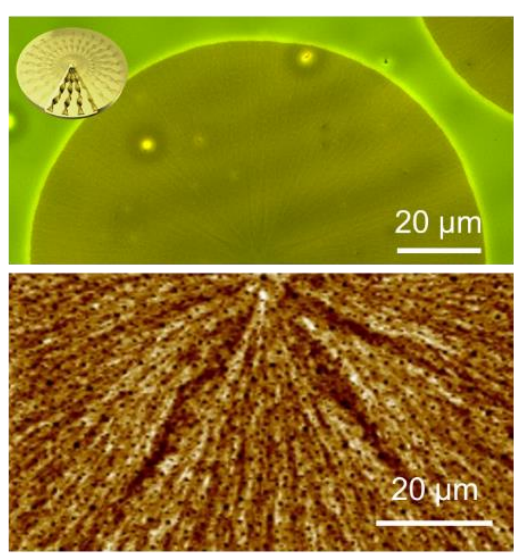

C

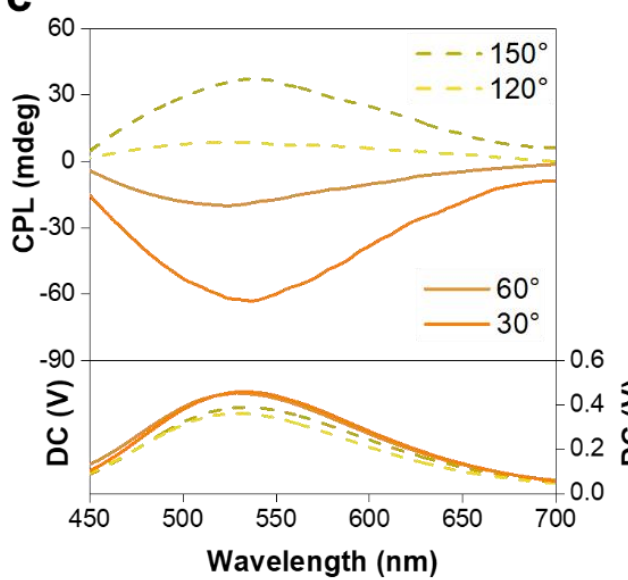

b

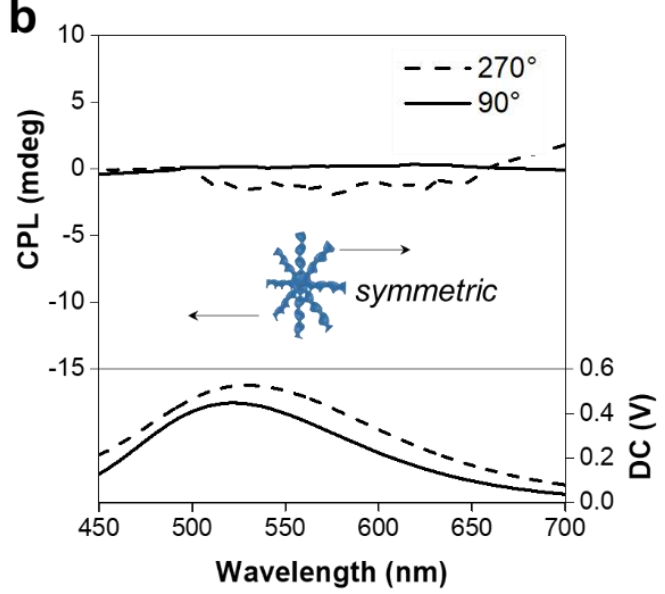

d

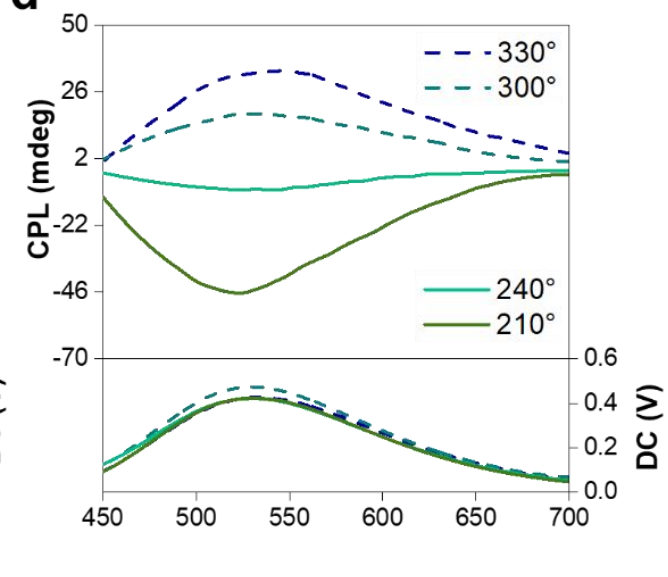

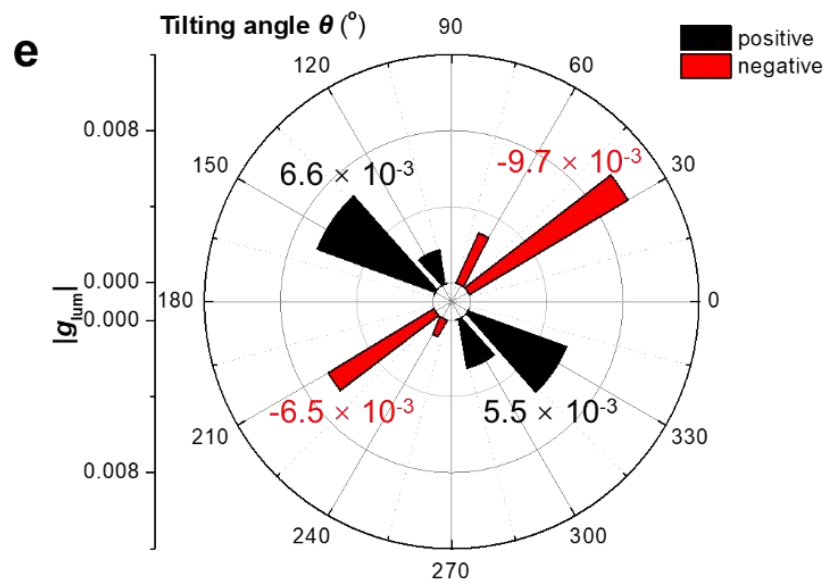

Figure S8. (a) Fluorescent micrograph (top) and AFM image (bottom) of BCC-Y-m from melt crystallization. (b) CPL spectra of BCC-Y-m at normal angle of $90^{\circ}$ and $270^{\circ} .90^{\circ}$ is front side and $270^{\circ}$ is back side. The film shows silent CPL signal at normal angles. (c, d) CPL spectra of BCC-Y-m as a function of $\theta$ angles by film tilting. (e) A polar diagram of dissymmetric values $\left|g_{\text {lum }}\right|$ corresponding to CPL spectra of BCC-Y-m plotted as a function of $\theta$. 
Fabrication of BCC-Y-m: BCC-Y-m films were prepared by melt-crystallization approach. Around 2 mg of BCC-Y was melted between quartz slides at $180^{\circ} \mathrm{C}$ for 3 min to remove any crystallization history. For a crystalline BCC-Y-m, the melt was cooled to and isothermally crystallized at $130^{\circ} \mathrm{C}$ for two hours.

Figure S8a shows the fluorescent and AFM images of BCC-Y-m spherulite, comprising of fiber-like polymer crystallites with strong sense of twisting. By contrast, BCC-Y-m film showed silent CPL signal at normal angles from front and back-side (Figure S8b), implying that the conical structure of chiral spherulite of BCC-Y indeed plays important role to produce the viewing-side dependent CPL at normal angles. Similar to BCC-Y, negative CPL $\left(R\right.$-CPL) was observed at right tilting $\left(0^{\circ}<\theta<90^{\circ}, 180^{\circ}<\theta<\right.$ $\left.270^{\circ}\right)$ and positive $\mathrm{CPL}(\mathrm{L}-\mathrm{CPL})$ was observed at left tilting angles $\left(90^{\circ}<\theta<180^{\circ}, 270^{\circ}<\theta<360^{\circ}\right)$ (Figure S8c, d). These results indicate that the CPL at tilting angle is originated from twisted crystallites, a structural component present in both samples. In addition, the values of $\left|g_{\text {lum }}\right|$ of BCC-Y-m at respective tilting angles (Figure S8e) is analogous to that of BCC-Y (Figure 3f, main text).
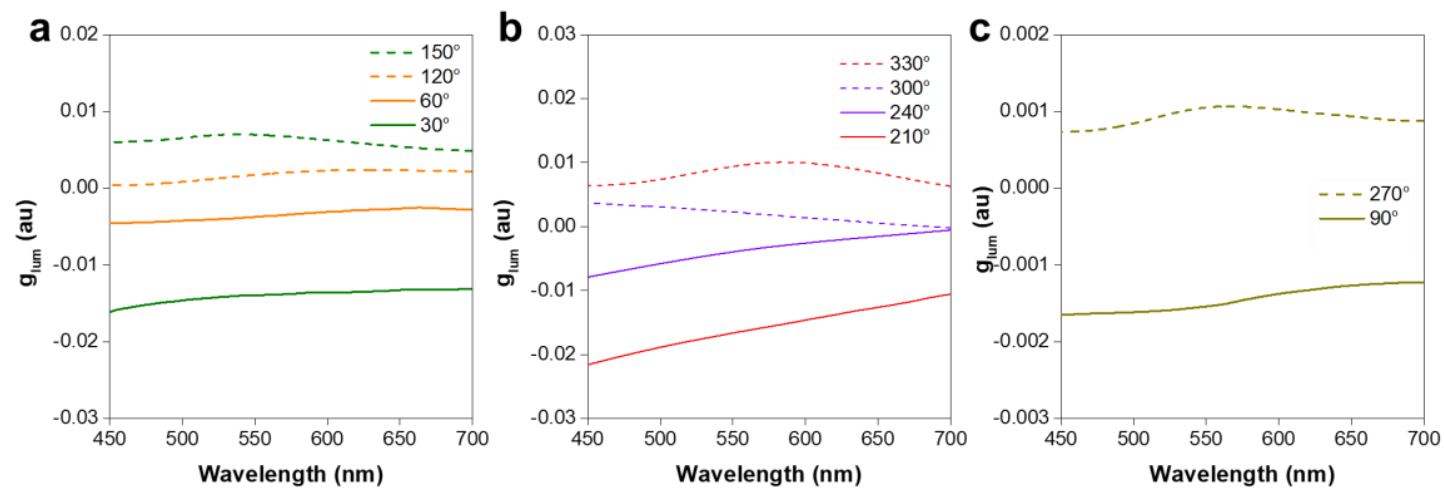

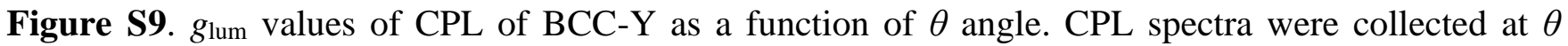
angles of (a) $30^{\circ}-150^{\circ}$, (b) $210^{\circ}-330^{\circ}$ and at normal angles of (c) $90^{\circ}$ and $270^{\circ}$. 
Table S1. Dissymmetry factors ( $\left.g_{\text {lum }}\right)$ of BCC-Y at various $\theta$ angles calculated at emission maximum.

\begin{tabular}{cccc}
\hline Tilting angle $\theta\left(^{\circ}\right)$ & $g_{\text {lum }}$ & Tilting angle $\theta\left(^{\circ}\right)$ & $g_{\text {lum }}$ \\
\hline 150 & $7.0 \times 10^{-3}$ & 330 & $9.5 \times 10^{-3}$ \\
120 & $1.7 \times 10^{-3}$ & 300 & $2.3 \times 10^{-3}$ \\
90 & $-1.5 \times 10^{-3}$ & 270 & $1.0 \times 10^{-3}$ \\
60 & $-3.7 \times 10^{-3}$ & 240 & $-3.9 \times 10^{-3}$ \\
30 & $-1.4 \times 10^{-2}$ & 210 & $-1.7 \times 10^{-2}$ \\
\hline
\end{tabular}
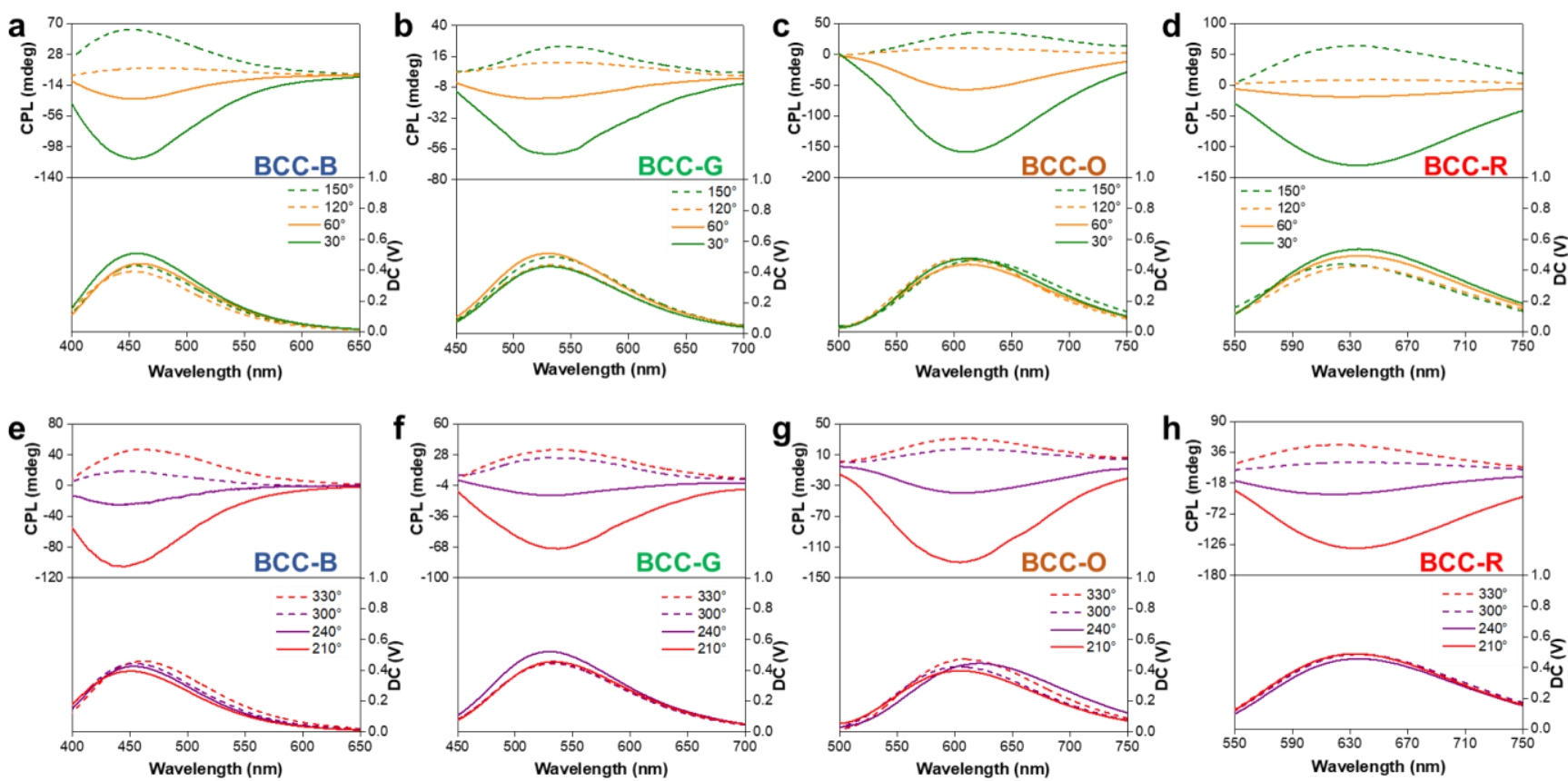

Figure S10. CPL spectra of (a and e) BCC-B, (b and f) BCC-G, (c and g) BCC-O and (d and h) BCC-R measured as a function of $\theta$ angle.
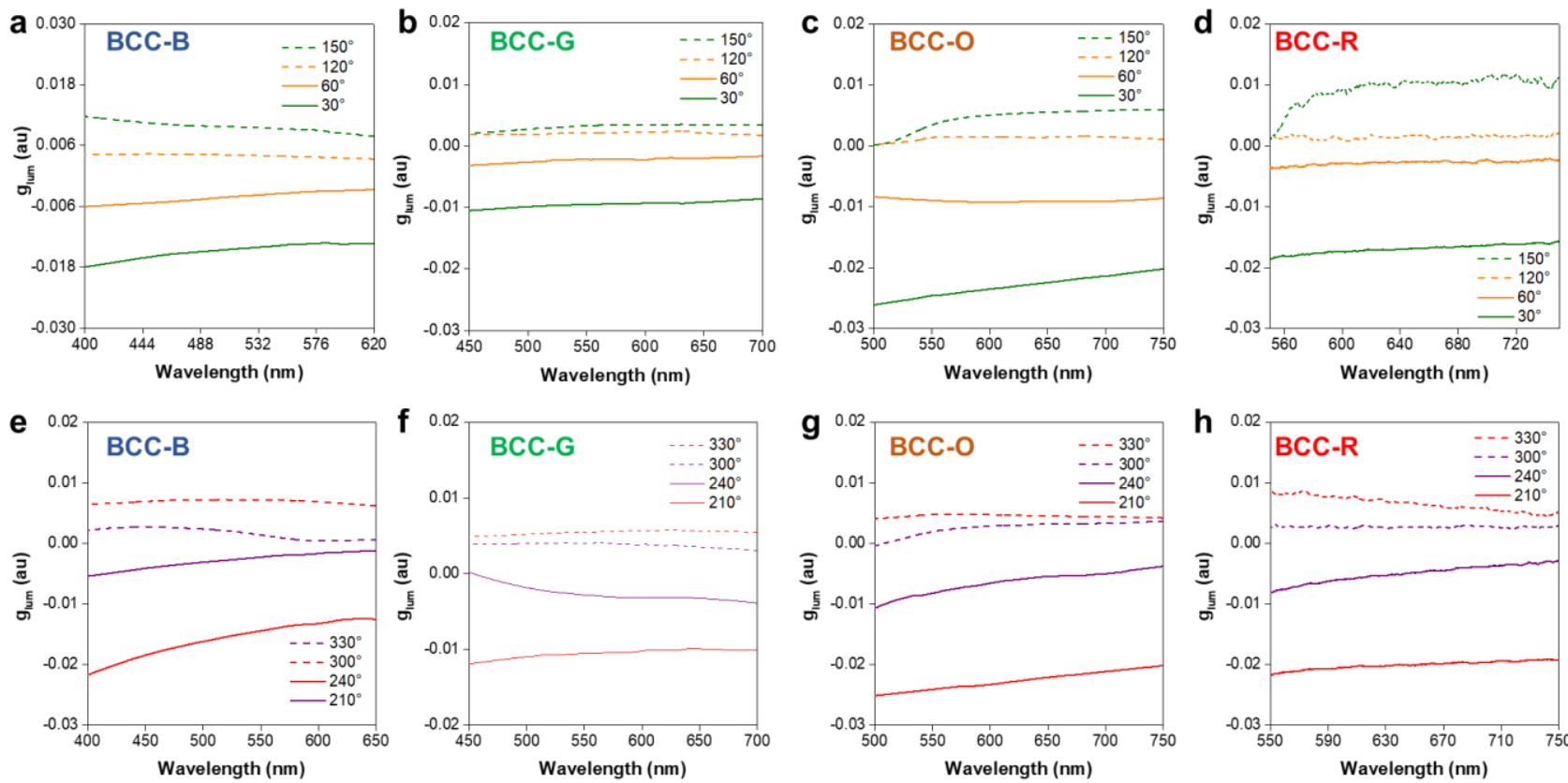


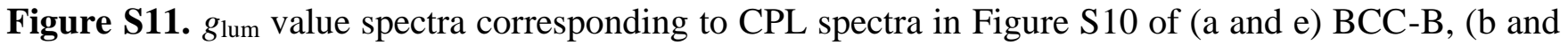
f) BCC-G, (c and g) BCC-O and (d and h) BCC-R measured as a function of $\theta$ angle.
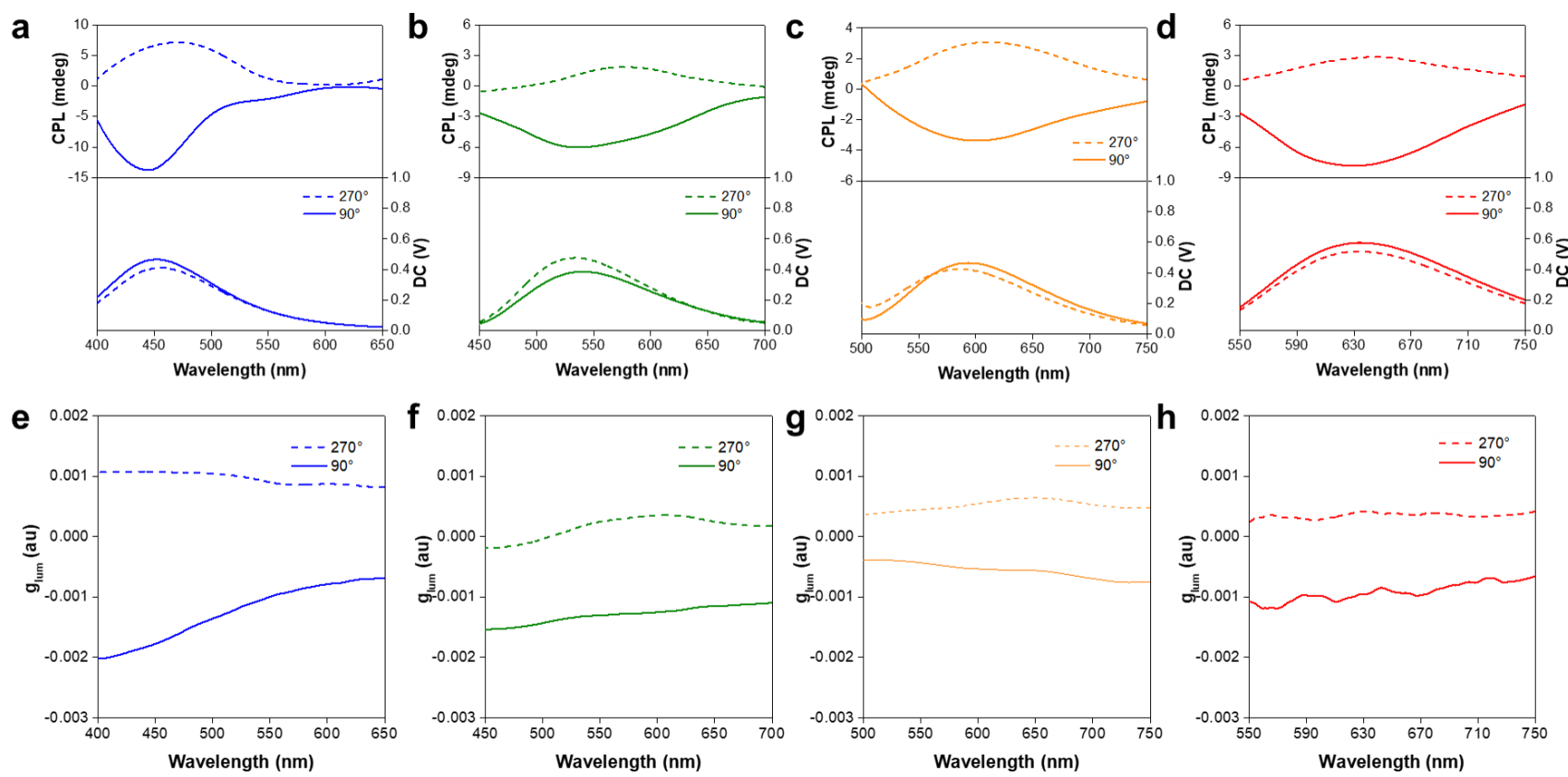

Figure S12. CPL spectra of (a) BCC-B, (b) BCC-G, (c) BCC-O, and (d) BCC-R measured at normal angles from front side $\left(90^{\circ}\right)$ and back-side $\left(270^{\circ}\right)$. The corresponding $g_{\text {lum }}$ values of (e) BCC-B, (f) BCC-G, (g) BCC-O and (h) BCC-R. At normal angles of measurement, BCC- $X$ exhibited viewing-side dependent CPL originating from the selective reflection by chiral spherulites.

Table S2. CPL experimental conditions for BCC- $X$ films.

\begin{tabular}{cccccc}
\hline Sample name & $\begin{array}{c}\text { BCC-B \& } \\
\text { BCC-C-TPE }\end{array}$ & BCC-G & BCC-Y & BCC-O & BCC-R \\
\hline Excitation Wavelength & $320 \mathrm{~nm}$ & $340 \mathrm{~nm}$ & $340 \mathrm{~nm}$ & $380 \mathrm{~nm}$ & $380 \mathrm{~nm}$ \\
\hline Excitation Slit Width & $3 \mathrm{~mm}$ & $3 \mathrm{~mm}$ & $3 \mathrm{~mm}$ & $0.1 \mathrm{~nm}$ \\
\hline Data Pitch & $0.1 \mathrm{~nm}$ & $0.1 \mathrm{~nm}$ & $0.1 \mathrm{~nm}$ & $750-500 \mathrm{~nm}$ & $750-500 \mathrm{~nm}$ \\
\hline Measure Range & $650-400 \mathrm{~nm}$ & $700-450 \mathrm{~nm}$ & $700-450 \mathrm{~nm}$ & $3 \mathrm{~mm}$ & $3 \mathrm{~mm}$ \\
\hline Emission Slit Width & $3 \mathrm{~mm}$ & $3 \mathrm{~mm}$ & $3 \mathrm{~mm}$ & $50 \mathrm{~nm} / \mathrm{min}$ \\
\hline Scan Speed & $50 \mathrm{~nm} / \mathrm{min}$ & $50 \mathrm{~nm} / \mathrm{min}$ & $5 \mathrm{~nm} / \mathrm{min}$ & $8 \mathrm{sec}$ \\
\hline D.I.T & $8 \mathrm{sec}$ & $8 \mathrm{sec}$ & $8 \mathrm{sec}$ &
\end{tabular}


<smiles>C[C@@H]1OC(=O)[C@@H](C)OC1=O</smiles><smiles>Oc1ccc(C(=C(c2ccccc2)c2ccccc2)c2ccccc2)cc1</smiles><smiles>CC(Oc1ccc(C(=C(c2ccccc2)c2ccccc2)c2ccccc2)cc1)C(=O)OC(C)C(C)C(C)C</smiles>

Figure S13. Synthetic route of TPE-PLLA by ring opening polymerization.

Table S3. Synthetic details of TPE-PLLA.

\begin{tabular}{ccccccccc}
\hline $\begin{array}{c}\text { L-Lactide } \\
(\mathrm{mg})\end{array}$ & $\begin{array}{c}\text { TPE-OH } \\
(\mathrm{mg})\end{array}$ & $\begin{array}{c}\mathrm{Sn}(\mathrm{Oct})_{2} \\
(\mu \mathrm{L})\end{array}$ & $\begin{array}{c}\text { Toluene } \\
(\mathrm{mL})\end{array}$ & $\begin{array}{c}T_{\mathrm{m}} \\
\left({ }^{\circ} \mathrm{C}\right)\end{array}$ & $\begin{array}{c}\text { Duration } \\
(\mathrm{h})\end{array}$ & $\begin{array}{c}M_{\mathrm{n}} \\
\left(\mathrm{g} \mathrm{mol}^{-1}\right)\end{array}$ & $\begin{array}{c}\mathrm{PDI}^{*} \\
(\%)\end{array}$ \\
\hline 350 & 5.6 & 5.6 & 1 & 130 & 24 & $1.2 \times 10^{4}$ & 1.12 & 68.6 \\
\hline
\end{tabular}

*Polydispersity index $(\mathrm{PDI})=M_{\mathrm{w}} / M_{\mathrm{n}}$
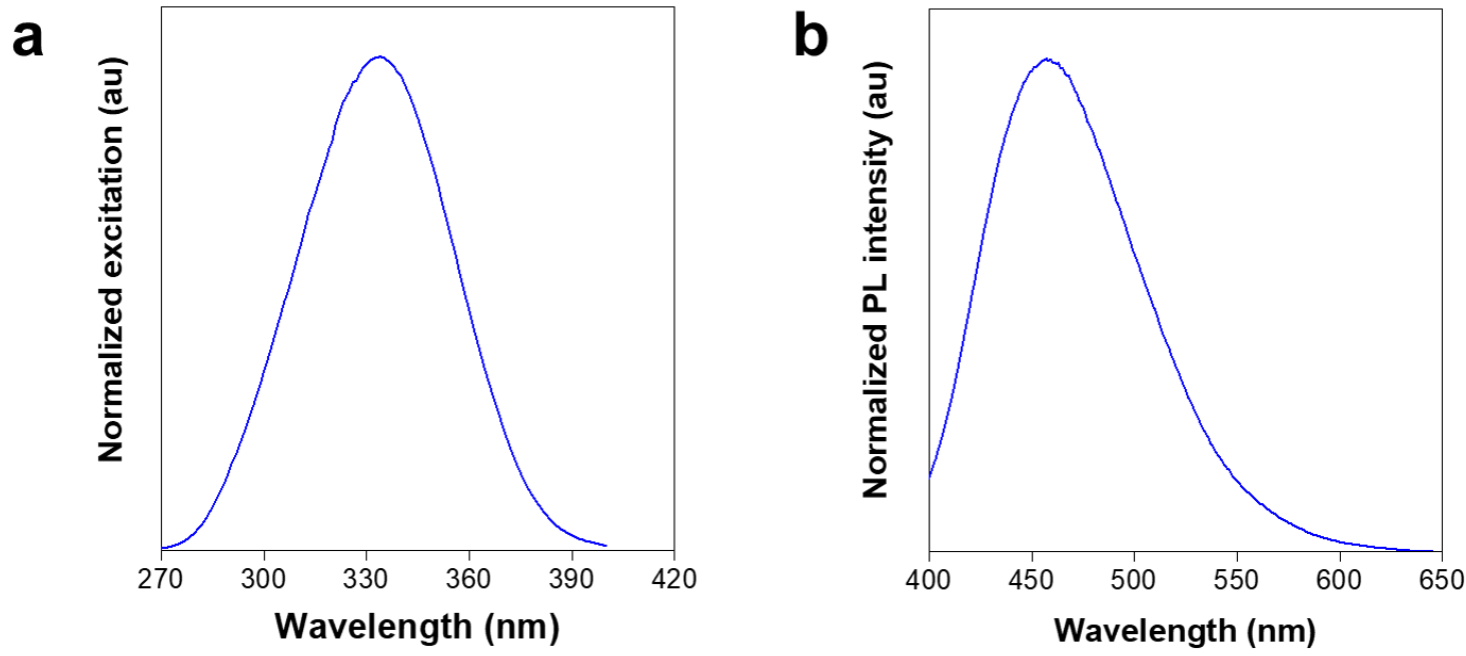

Figure S14. (a) Excitation and (b) emission spectra of TPE-PLLA powder. The emission was measured with excitation wavelength of $330 \mathrm{~nm}$. 
Figure S15. Fluorescent micrograph of BCC-c-TPE (crystalline TPE-PLLA, melt crystallization at $\left.130{ }^{\circ} \mathrm{C}\right)$. The circumferential and horizontal cracks observed in the spherulite are attributed to its relatively low molecular weight. ${ }^{1}$ Crystalline BCC-c-TPE films were prepared following the same thermal procedure with that of BCC-Y-m.

\section{References}

(1) Nurkhamidah, S.; Woo, E. M. Correlation of Crack Patterns and Ring Bands in Spherulites of Low Molecular Weight Poly(L-Lactic Acid). Colloid. Polym. Sci. 2012, 290, 275-288. 